\title{
Pooled Phase III safety analysis of sufentanil sublingual tablets for short-term treatment of moderate-to-severe acute pain
}

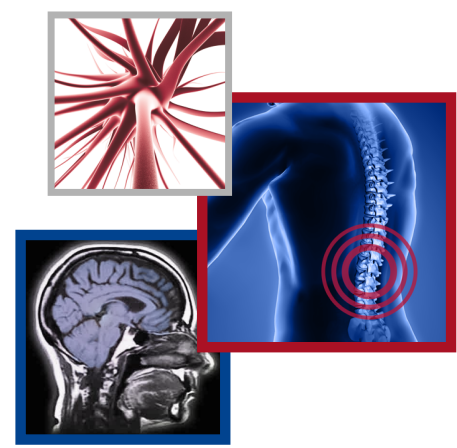

James R Miner*,1, Timothy I Melson², David Leiman³, Harold S Minkowitz ${ }^{4}$, Yu-Kun Chiang $^{5}$, Karen P DiDonato ${ }^{6}$ \& Pamela P Palmer

${ }^{1}$ Department of Emergency Medicine, Hennepin County Medical Center, Minneapolis, MN 55415, USA

${ }^{2}$ Department of Anesthesiology, Shoals Medical Trials, Inc., Sheffield, AL 35660, USA

${ }^{3}$ Clinical Assistant Professor of Surgery, University of Texas at Houston, \& Director of HD Research Corp, Houston, TX 77004, USA

${ }^{4}$ Director Clinical Investigation, HD Research Corp, Houston, TX 77004, USA

${ }^{5}$ President, Essence Sciences, San Jose, CA 95129, USA

${ }^{6}$ Department of Medical \& Clinical Affairs, AcelRx Pharmaceuticals, Redwood City, CA 94063, USA

*Author for correspondence: Tel.: +1 612873 8791; Fax: +1 612904 4241; James.Miner@hcmed.org

\footnotetext{
Practice points

- The sufentanil sublingual tablet (SST) offers an advantage over intravenous opioids with regard to its noninvasive route of administration.

- For the current analysis, safety data were pooled from the three Phase III studies of the SST $30 \mathrm{mcg}$ in patients following surgery or in an emergency department. An additional subset of postoperative patients who self-administered SST $15 \mathrm{mcg}$ in three Phase II and three Phase III studies were included in the pooled analysis if two SST 15-mcg doses were received within 20-25 min (30-mcg dose-equivalent).

- Study drug exposure data, adverse events (AEs) and oxygen saturation data, as well as time to SST dissolution and morphine equivalence were analyzed.

- A total of 804 patients were included in the safety analysis.

- AEs were experienced by $60.5 \%$ (SST) and $61.4 \%$ (placebo) and treatment-related AEs were experienced by $43.8 \%$ (SST) and $33.5 \%$ (placebo) (10.3\% difference; $95 \% \mathrm{Cl}: 2.0-18.6)$ of patients. Differences were significant for treatment-related AEs but not for AEs overall.

- Across all studies, nausea, which occurred in $34.1 \%$ of patients receiving SST, was the only moderate AE that occurred in $>5 \%$ of patients.

- No dose-dependent increase in oxygen desaturation events was observed with SST.

- Findings from the pooled analysis support that SST is well tolerated, with most AEs considered mild or moderate in severity, for the treatment of moderate-to-severe acute pain in medically supervised settings.
}

Aim: To evaluate the pooled safety of sufentanil sublingual tablets (SSTs) administered at 30-mcg dose equivalents over $\leq 72 \mathrm{~h}$ for moderate-to-severe acute pain management in medically supervised settings. Patients \& methods: Safety data from SST $30 \mathrm{mcg}$ Phase III studies were pooled with an additional patient subset from studies in which two SST $15 \mathrm{mcg}$ were self-administered within 20-25 min (30-mcg doseequivalent). Results: Analyses included 804 patients. Median (range) SST 30-mcg dosing over $24 \mathrm{~h}$ was 7.0 (1-15) tablets. Adverse events (AEs) were experienced by $60.5 \%$ (SST) and $61.4 \%$ (placebo) and treatmentrelated AEs by $43.8 \%$ (SST) and $33.5 \%$ (placebo; $10.3 \%$ difference; $95 \% \mathrm{Cl}$ : $2.0-18.6$ ) of patients. No dosedependent increase in oxygen desaturation was observed with SST. Conclusion: SST was well-tolerated, with most AEs considered mild or moderate in severity.

First draft submitted: 20 November 2018; Accepted for publication: 14 December 2018; Published online: 7 January 2019

Keywords: acute pain $\bullet$ adverse event $\bullet$ analgesia $\bullet$ emergency department $\bullet$ opioid $\bullet$ pooled safety analysis $\bullet$ postoperative $\bullet$ sufentanil sublingual tablet

Despite advances in pain treatment, acute pain management remains inadequate and $20-40 \%$ of patients still experience severe pain following surgery [1,2]. Pain also remains the most common complaint of patients presenting to the emergency department. From 1996 to 2015 in the USA, annual visits to the emergency department
Future Medicine 
increased from approximately 90 million [3] to 137 million [4], with nearly half of patients experiencing moderate $(25 \%)$ or severe $(20 \%)$ pain [5]. Commonly an intravenous (IV) opioid, such as morphine or hydromorphone, is used to manage moderate-to-severe acute pain, which requires the time and cost of initiating IV access and can produce undesirable side effects such as nausea, vomiting and respiratory depression [6]. The accumulation of the active metabolites of these opioids (i.e., morphine-3-glucuronide, morphine-6-glucuronide, hydromorphone-3glucuronide and hydromorphone-6-glucuronide) can add to the risk of these events [7].

Sufentanil, a synthetic opioid analgesic, is characterized by a high selectivity and affinity for mu-opioid receptors. As opposed to more commonly used opioids, including morphine and hydromorphone, sufentanil has no active metabolites. Sufentanil is 5-10 times more potent and twice as lipophilic as fentanyl [8,9], which allows for a small dosage form and rapid onset of analgesia when administered sublingually [10]. Small clinical studies have also shown that sufentanil may produce less respiratory depressive effects relative to its analgesic effects than other opioids [1114]. Therefore, sublingual sufentanil may be a viable noninvasive alternative in treating moderate-to-severe acute pain.

The sufentanil sublingual tablet (SST 15 mcg; Zalviso ${ }^{\circledR}$, Grünenthal GmbH, Aachen, Germany) was developed as a multiple-dose, patient-controlled analgesia (PCA) system for postoperative care. SST 15 mcg is intended for hospitalized patients who will likely require up to $72 \mathrm{~h}$ of acute pain management. Patients are able to self-administer SST $15 \mathrm{mcg}$ as needed via a hand-held device secured to the bed, with a 20-min lockout period between doses. As it is administered sublingually, SST $15 \mathrm{mcg}$ offers several advantages over IV administration, including an avoidance of IV-associated risks, greater patient mobility and a potential reduction in IV-related costs [15]. Phase III studies of SST $15 \mathrm{mcg}$ have demonstrated a favorable safety and tolerability profile, as well as efficacy in managing moderate-to-severe acute pain following major surgery compared with placebo [16,17] or IV morphine PCA [18]. More recently, a higher strength (SST 30 mcg; DSUVIA ${ }^{T M}$, AcelRx Pharmaceuticals, CA, USA; DZUVEO ${ }^{T M}$, FGK Representative Service GmbH, Munich, Germany), single-dose, sublingual tablet housed in a prefilled applicator (not for use beyond $48 \mathrm{~h}$ [European Medicines Agency summary of product characteristics] or $72 \mathrm{~h}$ [US prescribing information]) was developed to address the unique needs of pain management in battlefield settings, following ambulatory surgery and in the emergency department where there is high patient turnover and availability of IV access may be limited. In clinical studies, SST $30 \mathrm{mcg}$ provided a rapid onset of analgesia, with significant improvements in pain scores occurring within 15 min after administration [19-21]. In each Phase III study, SST $30 \mathrm{mcg}$ was well tolerated and adverse events (AEs) were generally considered mild, with no patients in the active treatment groups requiring naloxone.

Herein, we present a comprehensive safety analysis of data pooled from the Phase III SST 30 mcg studies supplemented with a selected pool of patients from the Phase II and Phase III SST 15 mcg studies, in which patients were treated with SST for $\leq 72 \mathrm{~h}$.

\section{Patients \& methods}

Study design

The pooled safety analysis included patients enrolled in the SST 30 mcg studies, as well as a select group of patients in SST $15 \mathrm{mcg}$ studies (if they received a second dose of SST $15 \mathrm{mcg}$ or placebo administered within 20-25 min after the first dose; Clinicaltrials.gov identifiers: NCT02356588, NCT02662556, NCT02447848, NCT00859313, NCT00612534, NCT00718081, NCT01539538, NCT01539642 and NCT01660763; Table 1). The use of SST $15 \mathrm{mcg}$ data was based on the establishment of bioequivalence of one SST 30-mcg tablet with two SST 15-mcg tablets dosed within 20 min of each other, as well as pharmacokinetic (PK) modeling, which concluded that this equivalence is expected if the dosing interval between two SST 15-mcg tablets is increased from 20 to 25 min [22]. All patients in the SST $30 \mathrm{mcg}$ and SST $15 \mathrm{mcg}$ studies had moderate-to-severe pain (pain intensity $\geq 4$ on an 11 -point numeric rating scale, where $0=$ no pain and $10=$ the worst possible pain). Patients were excluded from the studies if they were opioid tolerant (defined as $>15 \mathrm{mg}$ of oral morphine sulfate-equivalent daily), were dependent on supplemental oxygen at home or had documented sleep apnea. In the postoperative studies, patients with intractable vomiting in the recovery room were also excluded. Prior to dosing, patients were additionally excluded if they had respiratory difficulties (respiratory rate of $<8$ or $>24$ breaths per $\mathrm{min}$ ).

The protocols for all clinical studies used to generate data for the current analysis were approved by the corresponding Institutional Review Board for each study site and written informed consent was obtained from all patients. 


\begin{tabular}{|c|c|c|c|c|c|c|}
\hline $\begin{array}{l}\text { Procedure (Clinicaltrials.gov } \\
\text { identifier) }\end{array}$ & Study design ${ }^{\dagger}$ & Comparator & $\begin{array}{l}\text { Number of patients } \\
\text { in pooled safety } \\
\text { analysis/full study }\end{array}$ & Study duration & Rescue medication & Ref. \\
\hline \multicolumn{7}{|l|}{ SST $30 \mathrm{mcg}$} \\
\hline \multicolumn{7}{|l|}{ Phase III } \\
\hline $\begin{array}{l}\text { Ambulatory abdominal surgery } \\
\text { (NCT02356588) }\end{array}$ & $\begin{array}{l}\text { Multicenter, randomized } \\
\text { double-blind placebo controlled }\end{array}$ & Placebo & $161 / 161$ & $48 \mathrm{~h}$ & IV morphine & [19] \\
\hline $\begin{array}{l}\text { Emergency department trauma } \\
\text { or injury (NCT02662556) }\end{array}$ & Multicenter, open-label & None & $76 / 76$ & $\begin{array}{l}2 \mathrm{~h} \text { (single-dose cohort; } \\
\mathrm{n}=40 \text { ) } \\
5 \mathrm{~h} \text { (multiple-dose } \\
\text { cohort; } \mathrm{n}=36 \text { ) }\end{array}$ & $\begin{array}{l}\text { IV morphine or oral } \\
\text { oxycodone elixir }\end{array}$ & [21] \\
\hline $\begin{array}{l}\text { Inpatient and outpatient surgery } \\
\text { (NCT02447848) }\end{array}$ & Multicenter, open-label & None & $140 / 140$ & $12 \mathrm{~h}$ & IV morphine & [20] \\
\hline \multicolumn{7}{|l|}{ SST $15 \mathrm{mcg}^{\ddagger}$} \\
\hline \multicolumn{7}{|l|}{ Phase II } \\
\hline $\begin{array}{l}\text { Knee replacement } \\
\text { (NCT00859313) }\end{array}$ & Multicenter, open-label & None & $18 / 30$ & $12 \mathrm{~h}$ & None & \\
\hline $\begin{array}{l}\text { Total knee replacement } \\
\text { (NCT00612534) }\end{array}$ & $\begin{array}{l}\text { Multicenter, randomized } \\
\text { double-blind placebo controlled }\end{array}$ & $\begin{array}{l}\text { SST } 5 \text { mcg; SST } \\
10 \text { mcg; placebo }\end{array}$ & $27 / 94$ & $12 \mathrm{~h}$ & None & [23] \\
\hline $\begin{array}{l}\text { Open abdominal surgery } \\
\text { (NCT00718081) }\end{array}$ & $\begin{array}{l}\text { Multicenter, randomized } \\
\text { double-blind placebo controlled }\end{array}$ & SST 10 mcg; Placebo & $14 / 88$ & $12 \mathrm{~h}$ & None & [23] \\
\hline \multicolumn{7}{|l|}{ Phase III } \\
\hline $\begin{array}{l}\text { Open abdominal surgery or } \\
\text { knee/hip replacement } \\
\text { (NCT01539538) }\end{array}$ & $\begin{array}{l}\text { Multicenter, randomized } \\
\text { double-blind active control }\end{array}$ & IV morphine & $94 / 357$ & $72 \mathrm{~h}$ & IV morphine & [18] \\
\hline $\begin{array}{l}\text { Open abdominal surgery } \\
\text { (NCT01539642) }\end{array}$ & $\begin{array}{l}\text { Multicenter, randomized } \\
\text { double-blind placebo controlled }\end{array}$ & Placebo & $78 / 172$ & $72 \mathrm{~h}$ & IV morphine & [17] \\
\hline $\begin{array}{l}\text { Total knee or hip replacement } \\
\text { (NCT01660763) }\end{array}$ & $\begin{array}{l}\text { Multicenter, randomized } \\
\text { double-blind placebo controlled }\end{array}$ & Placebo & $196 / 419$ & $72 \mathrm{~h}$ & IV morphine & [16] \\
\hline
\end{tabular}

\section{Studies of healthcare professional administration of SST $30 \mathrm{mcg}$}

Data from SST $30 \mathrm{mcg}$ studies were pooled from patients following abdominal surgery (placebo-controlled; study duration of $24 \mathrm{~h}$ with extension to $48 \mathrm{~h}$ if needed) [19], postoperative patients from various surgeries including skeletal and soft-tissue, (single-arm; study duration of $12 \mathrm{~h}$ ) [20] and patients being treated for injury or trauma in emergency departments (single-arm; study duration up to $5 \mathrm{~h}$ ) [21] (see Table 1).

In all SST $30 \mathrm{mcg}$ studies, SST was administered by a healthcare professional via a single-dose applicator only upon patient request for pain relief, subject to a minimum 1-h redosing interval. Rescue analgesia for the postoperative studies was $1 \mathrm{mg}$ IV morphine, no more frequently than hourly, as needed [19,20]. Patients in the emergency department study were provided rescue analgesia of either IV morphine $(0.05 \mathrm{mg} / \mathrm{kg})$ or oral oxycodone elixir $(0.1 \mathrm{mg} / \mathrm{kg})$, no more frequently than hourly, as needed [21].

Studies of PCA with SST $15 \mathrm{mcg}$ (30-mcg dose-equivalent)

Data from six SST $15 \mathrm{mcg}$ studies in postoperative patients were included in the pooled analysis (see Table 1), five of which were previously reported [16-18,23]. Study periods varied from 12 to $72 \mathrm{~h}$. Four of the studies were double-blind, placebo-controlled studies $[16,17,23]$ and two were open-label studies including a comparison against IV morphine PCA [18].

Safety analyses

Study drug exposure, patient discontinuations, AEs and oxygen desaturation events (all patients were continuously monitored with a pulse oximeter) were included in this analysis. All enrolled patients who received at least one dose of study drug were included in the analyses and summaries of safety data. Discontinuations and AEs were analyzed over the study treatment period (after the initial study drug dosing for both the SST $30 \mathrm{mcg}$ and SST $15 \mathrm{mcg}$ 


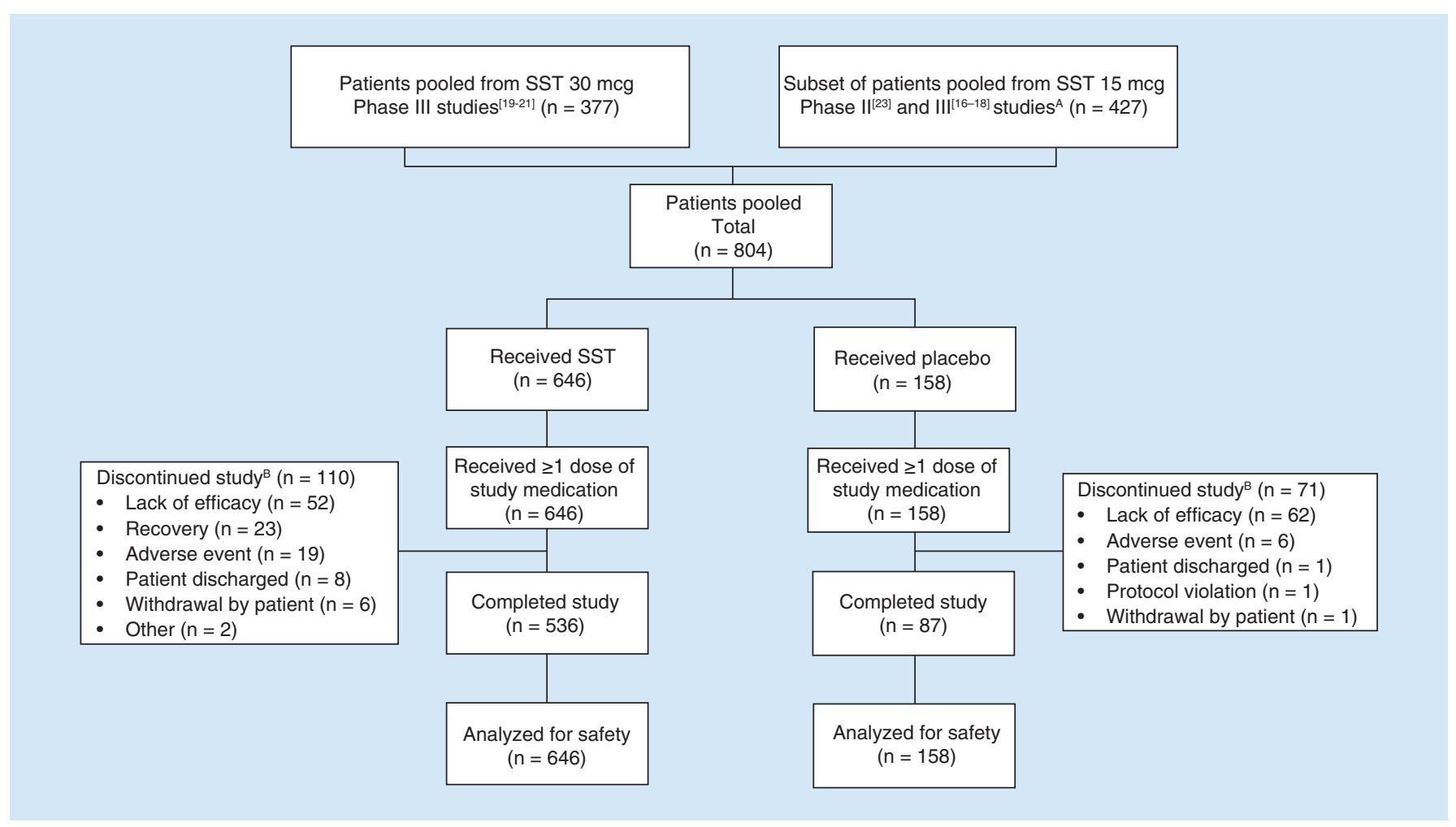

Figure 1. Disposition of patients included in the pooled safety analysis. (A) Patients who received two doses of SST 15 mcg within 20-25 min (30-mcg dose-equivalent). (B) Prior to 24 -h assessment.

SST: Sufentanil sublingual tablet.

studies) and within $12 \mathrm{~h}$ after study drug discontinuation. To obtain an IV morphine equivalence for SST, drug utilization was compared in the IAP309 study in which patients received either SST 15 mcg or IV morphine.

\section{Tablet erosion \& bioadhesion}

A reasonably rapid tablet erosion time is considered important for patient convenience (i.e., minimal interference with eating, drinking and talking), therefore erosion of the SST (data not previously reported) was monitored in a PK study [26]. Specifically, subjects were asked every 2 min to open their mouths and raise their tongues so the clinician could observe the sublingual cavity and record their observations. The tablets were allowed to dissolve and were not crushed, chewed or swallowed, and subjects were requested to minimize talking for $10 \mathrm{~min}$ after the SST had been administered.

\section{Statistical analysis (pooled data)}

The baseline, dosing, termination and safety data included in this pooled analysis were summarized descriptively. For the analysis of termination data due to AEs and lack of efficacy, the difference in proportion and its $95 \% \mathrm{CI}$ based on the normal distribution between SST and placebo treatments were calculated. For the analysis of AE data, the difference in proportion and its 95\% CI based on the normal distribution between SST and placebo treatments, as well as between SST $15 \mathrm{mcg}$ and SST $30 \mathrm{mcg}$ treatments, were calculated. All data analyses were performed using SAS for Windows, Release 9.1.

\section{Results}

Baseline demographics \& patient disposition

Overall, 804 patients were included in the pooled safety analysis. The most common $(>1 \%)$ reasons for discontinuation were lack of efficacy (14.2\%), AEs (3.1\%), recovery (2.9\%; a strong opioid was no longer indicated), patient discharged (1.1\%) and withdrawal from the study by the patient (0.9\%) (Figure 1). Compared with patients receiving SST, a larger proportion of patients receiving placebo discontinued due to lack of efficacy (39.2\% placebo 


\begin{tabular}{|c|c|c|c|c|c|}
\hline Characteristics & SST $15 \mathrm{mcg}^{\dagger}(\mathrm{n}=323)$ & SST $30 \mathrm{mcg}(n=323)$ & Total SST $(n=646)$ & Total placebo $(n=158)$ & Total $(n=804)$ \\
\hline \multicolumn{6}{|c|}{ Age group, years, $\mathrm{n}(\%)$} \\
\hline$<55$ & $57(17.6)$ & $223(69.0)$ & $280(43.3)$ & $78(49.4)$ & $358(44.5)$ \\
\hline 55 to $<65$ & $102(31.6)$ & $66(20.4)$ & $168(26.0)$ & $39(24.7)$ & $207(25.7)$ \\
\hline 65 to $<75$ & $100(31.0)$ & $26(8.0)$ & $126(19.5)$ & $25(15.8)$ & $151(18.8)$ \\
\hline$\geq 75$ & $64(19.8)$ & $8(2.5)$ & $72(11.1)$ & $16(10.1)$ & $88(10.9)$ \\
\hline \multicolumn{6}{|l|}{ Age, years } \\
\hline Median (range) & $65.0(19-86)$ & $48.0(18-84)$ & $57.0(18-86)$ & $55.0(20-87)$ & $56.0(18-87)$ \\
\hline Mean (SD) & $64.0(12.1)$ & $47.2(13.2)$ & $55.6(15.2)$ & $53.5(15.8)$ & $55.2(15.4)$ \\
\hline \multicolumn{6}{|l|}{ Sex, $n(\%)$} \\
\hline Female & $209(64.7)$ & $178(55.1)$ & $387(59.9)$ & $103(65.2)$ & $490(60.9)$ \\
\hline Male & $114(35.3)$ & $145(44.9)$ & $259(40.1)$ & $55(34.8)$ & $314(39.1)$ \\
\hline \multicolumn{6}{|l|}{ Race, n (\%) } \\
\hline White & $279(86.4)$ & $238(73.7)$ & $517(80.0)$ & 121 (76.6) & $638(79.4)$ \\
\hline $\begin{array}{l}\text { Black or } \\
\text { African-American }\end{array}$ & $39(12.1)$ & $67(20.7)$ & $106(16.4)$ & $26(16.5)$ & $132(16.4)$ \\
\hline Other & $5(1.5)$ & $17(5.3)$ & $23(3.6)$ & $11(7.0)$ & $34(4.2)^{\ddagger}$ \\
\hline \multicolumn{6}{|l|}{ Ethnicity, n (\%) } \\
\hline Hispanic or Latino & $10(3.1)$ & $76(23.5)$ & $86(13.3)$ & $21(13.3)$ & $107(13.3)$ \\
\hline \multicolumn{6}{|c|}{ BMI group, $\mathrm{n}(\%), \mathrm{kg} / \mathrm{m}^{2}$} \\
\hline$<30$ & $176(54.5)$ & $199(62.4)$ & $375(58.4)$ & $89(56.3)$ & $464(58.0)$ \\
\hline $30-40$ & $119(36.8)$ & $101(31.7)$ & $220(34.3)$ & $62(39.2)$ & $282(35.3)$ \\
\hline$>40$ & $28(8.7)$ & $19(6.0)$ & $47(7.3)$ & $7(4.4)$ & $54(6.8)$ \\
\hline \multicolumn{6}{|l|}{$\mathrm{BMI}, \mathrm{kg} / \mathrm{m}^{2}$} \\
\hline Median (range) & $29.3(17.5-62.0)$ & $27.5(17.5-67.0)$ & $28.7(17.5-67.0)$ & $29.0(15.8-52.0)$ & $28.7(15.8-67.0)$ \\
\hline Mean (SD) & $30.3(6.9)$ & $29.3(6.9)$ & $29.8(6.9)$ & $30.0(5.7)$ & $29.9(6.7)$ \\
\hline \multicolumn{6}{|c|}{ ASA classification, n (\%) } \\
\hline 1 & NR & $156(48.3)$ & $156(48.3)$ & $37(68.5)$ & $193(51.2)$ \\
\hline II & $\mathrm{NR}$ & $137(42.4)$ & $137(42.4)$ & $13(24.1)$ & $150(39.8)$ \\
\hline III & $\mathrm{NR}$ & $30(9.3)$ & $30(9.3)$ & $4(7.4)$ & $34(9.0)$ \\
\hline \multicolumn{6}{|l|}{ Surgery type, $n(\%)$} \\
\hline Abdominal & $74(22.9)$ & $190(58.8)$ & $264(40.9)$ & $87(55.1)$ & $351(43.7)$ \\
\hline Orthopedic & $247(76.5)$ & $28(8.7)$ & $275(42.6)$ & $69(43.7)$ & $344(42.8)$ \\
\hline $\begin{array}{l}\text { Nonsurgical (trauma } \\
\text { patients) }\end{array}$ & 0 & $76(23.5)$ & $76(11.8)$ & 0 & $76(9.5)$ \\
\hline Other surgery & $2(0.6)$ & $29(9.0)$ & $31(4.8)$ & $2(1.3)$ & $33(4.1)$ \\
\hline
\end{tabular}

vs $8.0 \%$ SST); however, the rates of discontinuation due to AEs were similar, albeit low (3.8\% placebo vs $2.9 \%$ SST).

Across all studies, the median (range) age was 56.0 (18.0-87.0) years and the majority of patients were female $(60.9 \%)$, white $(79.4 \%)$, had a BMI $<30(58.0 \%)$ and had undergone either abdominal (43.7\%) or orthopedic $(42.8 \%)$ surgery (Table 2) [16-21,23]. Compared with patients who received SST 30 mcg, patients in the SST 15 mcg studies were older (64.0 vs 47.2 years) and had a higher BMI (30.3 vs $29.3 \mathrm{~kg} / \mathrm{m}^{2}$ ). A greater percentage of patients who received SST $15 \mathrm{mcg}$ had major orthopedic surgery compared with patients who received SST $30 \mathrm{mcg}$ (76.5 vs $8.7 \%$ ). Further, $23.5 \%$ of patients who received SST $30 \mathrm{mcg}$ were nonsurgical trauma patients in the emergency department. 
Study drug doses

Across the studies, SST $30 \mathrm{mcg}$ was administered to 178 patients for $\geq 6 \mathrm{~h}, 93$ patients for $\geq 12 \mathrm{~h}, 25$ patients for $\geq 24 \mathrm{~h}$ and one patient for $\geq 48 \mathrm{~h}$. SST $15 \mathrm{mcg}$ was self-administered via the PCA system by 292 patients for $\geq 6 \mathrm{~h}$, 255 patients for $\geq 12 \mathrm{~h}, 226$ patients for $\geq 24 \mathrm{~h}$ and 101 patients for $\geq 48 \mathrm{~h}$. The median (range) number of SST 30 -mcg doses over the first $24 \mathrm{~h}$ in which patients remained in the study was $7.0(1-15)$ tablets or $210(30-450)$ mcg, while the median (range) number of SST 15-mcg doses over this same time period was 25.0 (2-55) tablets or $375(30-825) \mathrm{mcg}$, which was understandably higher given the more extensive surgeries studied with this PCA system and the higher dosing available with the SST $15 \mathrm{mcg}$ PCA system (up to $45 \mathrm{mcg} / \mathrm{h}$ ).

Safety \& AEs

All AEs

Overall, $60.7 \%$ of patients experienced at least one AE. The most common AEs experienced by $\geq 5 \%$ of all patients were nausea $(35.3 \%)$, headache $(9.7 \%)$, pyrexia $(8.6 \%)$, vomiting $(7.3 \%)$ and anemia $(4.5 \%)$. AEs were experienced by 60.5 and $61.4 \%$ of patients receiving any SST dose and placebo, respectively $(-0.9 \%$ difference [95\% CI: -9.4-7.6]) (Table 3) [16-21,23].

Most of the AEs were rated as mild in severity by the clinical investigators. Nausea was the only moderate-rated AE that occurred in $>5 \%$ of all patients, including in $9.0 \%$ receiving SST $30 \mathrm{mcg}, 25.1 \%$ receiving SST $15 \mathrm{mcg}, 17.0 \%$ receiving any SST dose and $17.1 \%$ receiving placebo. Combining all studies, 15 of the 804 patients experienced a severe AE. Eight patients who received SST $30 \mathrm{mcg}$ experienced severe AEs of nausea $(n=4)$, headache $(n=2)$, procedural nausea $(n=2)$, procedural vomiting $(n=2)$, confusional state $(n=1)$, dizziness $(n=1)$, dry mouth $(\mathrm{n}=1)$, euphoric $\operatorname{mood}(\mathrm{n}=1)$ and vomiting $(\mathrm{n}=1)$. Four patients who received SST 15 mcg experienced severe AEs of oxygen saturation decreased $(n=2)$, hepatic enzyme increased $(n=1)$, nausea $(n=1)$ and postoperative ileus $(\mathrm{n}=1)$. Three patients who received placebo experienced severe AEs of procedural nausea $(\mathrm{n}=1)$, hemiparesis $(\mathrm{n}=1)$ and abdominal pain $(\mathrm{n}=1)$.

In all, nine serious AEs were experienced by a total of seven (0.9\%) patients receiving SST $15 \mathrm{mcg}$ (four patients), placebo (two patients) or SST $30 \mathrm{mcg}$ (one patient) (Table 4).

There were no deaths in studies of SST $30 \mathrm{mcg}$. In studies of SST $15 \mathrm{mcg}$, there were two deaths, both of which occurred at least 18 days after discontinuation of study drug and were considered unrelated to treatment by the study investigator. One death was due to acute renal failure in a patient 30 days following discontinuation of SST $15 \mathrm{mcg}$. The other death was due to severe sepsis and occurred in a patient treated with IV morphine PCA in the active comparator study (because this patient received morphine and not SST, this patient was not included in the pooled safety analysis).

\section{Treatment-related AEs}

For all studies combined, $41.8 \%$ of patients experienced at least one AE considered related to treatment. Treatmentrelated AEs experienced by $\geq 5 \%$ of all patients were nausea (27.2\%), vomiting (6.0\%) and headache (5.2\%). Overall, $283(43.8 \%)$ patients who received any dose of SST experienced an AE related to treatment compared with 53 (33.5\%) patients who received placebo (10.3\% difference [95\% CI: 2.0-18.6]) (Table 3) [16-21,23].

\section{AEs of special interest: respiratory \& neuropsychiatric AEs}

Most respiratory and neuropsychiatric AEs observed in the SST and placebo groups were mild to moderate and no opioid reversal agent (e.g., naloxone) was required for any patient receiving SST $30 \mathrm{mcg}$, while three patients who received SST $15 \mathrm{mg}$ required naloxone, including the patient with the serious AE of oxygen saturation decreased in the Phase III orthopedic study [16] (see Table 4). One additional patient had a serious respiratory $\mathrm{AE}$ of hypoxia but did not require naloxone (this patient had a pulmonary embolism causing the event; Table 4). Overall, 10/646 (1.5\%) patients treated with SST discontinued a study due to a respiratory AE, which included six patients with oxygen desaturation (including the patient with the serious $\mathrm{AE}$ ) and one patient each with bradypnea, hypoventilation, hypoxia and respiratory rate increased.

Three $(0.5 \%)$ patients receiving SST experienced neuropsychiatric events considered severe and related to study treatment, including dizziness, headache and confusional state $(\mathrm{n}=1)$, euphoric $\operatorname{mood}(\mathrm{n}=1)$ and headache $(\mathrm{n}=1)$. Twelve (1.9\%) patients receiving SST discontinued due to a neuropsychiatric event, including sedation $(\mathrm{n}=4)$, agitation $(\mathrm{n}=2)$, anxiety $(\mathrm{n}=2)$ confusional state $(\mathrm{n}=2)$ and dizziness $(\mathrm{n}=2)$. One patient experienced a serious $\mathrm{AE}$ of confusional state following a pulmonary embolism (Table 4). 


\begin{tabular}{|c|c|c|c|c|c|}
\hline Patients, n (\%) & $\begin{array}{l}\text { SST } 15 \mathrm{mcg}^{\ddagger} \\
(\mathrm{n}=323)\end{array}$ & $\begin{array}{l}\text { SST } 30 \mathrm{mcg} \\
(\mathrm{n}=323)\end{array}$ & Total SST $\$(n=646)$ & $\begin{array}{l}\text { Total placebo } \\
(n=158)\end{array}$ & $\begin{array}{l}\text { SST }^{\S} \text { vs placebo, } \\
\text { difference, \% (95\% Cl) }\end{array}$ \\
\hline \multicolumn{6}{|l|}{ All AEs } \\
\hline \multicolumn{6}{|l|}{ Number of AEs } \\
\hline None & $62(19.2)$ & $193(59.8)$ & $255(39.5)$ & $61(38.6)$ & \\
\hline$\geq 1$ & $261(80.8)$ & $130(40.2)$ & $391(60.5)$ & $97(61.4)$ & $-0.9(-9.4$ to 7.6$)$ \\
\hline \multicolumn{6}{|c|}{ All AEs $\mathbb{I}$ ( $\geq 2 \%$ of patients in any study group) } \\
\hline Nausea & $155(48.0)$ & $80(24.8)$ & $235(36.4)$ & $49(31.0)$ & $5.4(-2.7$ to 13.5$)$ \\
\hline Headache & $34(10.5)$ & $29(9.0)$ & $63(9.8)$ & $15(9.5)$ & $0.3(-4.8$ to 5.4$)$ \\
\hline Pyrexia & $56(17.3)$ & 0 & $56(8.7)$ & $13(8.2)$ & $0.5(-4.3$ to 5.3$)$ \\
\hline Vomiting & $41(12.7)$ & $12(3.7)$ & $53(8.2)$ & $6(3.8)$ & $4.4(0.7,8.1)$ \\
\hline Anemia & $33(10.2)$ & 0 & $33(5.1)$ & $3(1.9)$ & $3.2(0.5,5.9)$ \\
\hline Dizziness & $18(5.6)$ & $13(4.0)$ & $31(4.8)$ & $4(2.5)$ & $2.3(-0.6$ to 5.2$)$ \\
\hline Pruritus & $24(7.4)$ & $7(2.2)$ & $31(4.8)$ & $4(2.5)$ & $2.3(-0.6$ to 5.2$)$ \\
\hline Hypotension & $14(4.3)$ & $8(2.5)$ & $22(3.4)$ & $6(3.8)$ & $-0.4(-3.7$ to 2.9$)$ \\
\hline Oxygen saturation decreased & $20(6.2)$ & $6(1.9)$ & $26(4.0)$ & $1(0.6)$ & 3.4 (1.5 to 5.3$)$ \\
\hline Constipation & $20(6.2)$ & $1(0.3)$ & $21(3.3)$ & $1(0.6)$ & 2.7 (0.9 to 4.5$)$ \\
\hline Hypertension & $11(3.4)$ & $3(0.9)$ & $14(2.2)$ & $5(3.2)$ & $-1.0(-4.0$ to 2.0$)$ \\
\hline Insomnia & $12(3.7)$ & 0 & $12(1.9)$ & $3(1.9)$ & $0.0(-2.4$ to 2.4$)$ \\
\hline Tachycardia & $9(2.8)$ & $4(1.2)$ & $13(2.0)$ & $2(1.3)$ & $0.7(-1.4$ to 2.8$)$ \\
\hline Hypocalcemia & $12(3.7)$ & 0 & $12(1.9)$ & $2(1.3)$ & $0.6(-1.5$ to 2.7$)$ \\
\hline Leukocytosis & $11(3.4)$ & 0 & $11(1.7)$ & $3(1.9)$ & $-0.2(-2.6$ to 2.2$)$ \\
\hline Sinus tachycardia & $11(3.4)$ & 0 & $11(1.7)$ & $2(1.3)$ & $0.4(-1.6$ to 2.4$)$ \\
\hline Somnolence & $3(0.9)$ & $7(2.2)$ & $10(1.5)$ & $3(1.9)$ & $-0.4(-2.7$ to 1.9$)$ \\
\hline Anemia postoperative & $10(3.1)$ & 0 & $10(1.5)$ & $1(0.6)$ & $0.9(-0.6$ to 2.4$)$ \\
\hline Body temperature increased & $10(3.1)$ & 0 & $10(1.5)$ & $1(0.6)$ & $0.9(-0.6$ to 2.4$)$ \\
\hline Confusional state & $8(2.5)$ & $1(0.3)$ & $9(1.4)$ & $2(1.3)$ & $0.1(-1.9$ to 2.1$)$ \\
\hline Dyspepsia & $9(2.8)$ & $1(0.3)$ & $10(1.5)$ & $1(0.6)$ & $0.9(-0.6$ to 2.4$)$ \\
\hline Hypoalbuminemia & $10(3.1)$ & 0 & $10(1.5)$ & $1(0.6)$ & $0.9(-0.6$ to 2.4$)$ \\
\hline Hypokalemia & $10(3.1)$ & 0 & $10(1.5)$ & $1(0.6)$ & $0.9(-0.6$ to 2.4$)$ \\
\hline Muscle spasms & $7(2.2)$ & $1(0.3)$ & $8(1.2)$ & $3(1.9)$ & $-0.7(-3.0$ to 1.6$)$ \\
\hline Anxiety & $8(2.5)$ & 0 & $8(1.2)$ & $2(1.3)$ & $-0.1(-2.1$ to 1.9$)$ \\
\hline Flatulence & $1(0.3)$ & $4(1.2)$ & $5(0.8)$ & $5(3.2)$ & $-2.4(-5.2$ to 0.4$)$ \\
\hline Hyponatremia & $8(2.5)$ & 0 & $8(1.2)$ & $1(0.6)$ & $0.6(-0.9$ to 2.1$)$ \\
\hline Hypoxia & $6(1.9)$ & $1(0.3)$ & $7(1.1)$ & $2(1.3)$ & $-0.2(-2.1$ to 1.7$)$ \\
\hline Urinary retention & $8(2.5)$ & 0 & $8(1.2)$ & 0 & $1.2(0.4$ to 2.0$)$ \\
\hline Pharyngolaryngeal pain & $5(1.5)$ & $2(0.6)$ & $7(1.1)$ & 0 & $1.1(0.3$ to 1.9$)$ \\
\hline Procedural nausea & 0 & $3(0.9)$ & $3(0.5)$ & $3(1.9)$ & $-1.4(-3.6$ to 0.8$)$ \\
\hline Sedation & $5(1.5)$ & 0 & $5(0.8)$ & 0 & $0.8(0.1$ to 1.5$)$ \\
\hline \multicolumn{6}{|l|}{$\mathrm{AEs}$ related ${ }^{\dagger}$ to study treatment } \\
\hline \multicolumn{6}{|l|}{ Number of related AEs } \\
\hline None & 145 (44.9) & $218(67.5)$ & $363(56.2)$ & $105(66.5)$ & \\
\hline$\geq 1$ & $178(55.1)$ & $105(32.5)$ & $283(43.8)$ & $53(33.5)$ & 10.3 (2.0 to 18.6$)$ \\
\hline \multicolumn{6}{|c|}{ AEs $\mathbb{I}$ related to treatment ( $\geq 2 \%$ of patients in any study group) } \\
\hline Nausea & $110(34.1)$ & $74(22.9)$ & $184(28.5)$ & $35(22.2)$ & $6.3(-1.1$ to 13.7$)$ \\
\hline Vomiting & $32(9.9)$ & $10(3.1)$ & $42(6.5)$ & $6(3.8)$ & $2.7(-0.8$ to 6.2$)$ \\
\hline \multicolumn{6}{|c|}{$\begin{array}{l}\dagger \text { Related AEs are defined as possibly or probably related to study drug. } \\
\ddagger \text { A subset of patients who received two doses of SST } 15 \mathrm{mcg} \text { within } 20-25 \mathrm{~min} \text { (30-mcg dose equivalent). } \\
\S \text { SST includes } 15 \mathrm{mcg}(\mathrm{n}=323) \text { and } 30 \mathrm{mcg}(\mathrm{n}=363) \text { doses. } \\
\mathbb{I}_{\text {AE mapping was based on Medical Dictionary for Regulatory Activities version } 11.0 \text {. }} \\
\text { AE: Adverse event; NA: Not applicable; SST: Sufentanil sublingual tablet. }\end{array}$} \\
\hline
\end{tabular}




\begin{tabular}{|c|c|c|c|c|c|}
\hline Patients, n (\%) & $\begin{array}{l}\text { SST } 15 \mathrm{mcg}^{\ddagger} \\
(\mathrm{n}=323)\end{array}$ & $\begin{array}{l}\text { SST } 30 \mathrm{mcg} \\
(\mathrm{n}=323)\end{array}$ & Total SST $^{\S}(n=646)$ & $\begin{array}{l}\text { Total placebo } \\
(n=158)\end{array}$ & $\begin{array}{l}\text { SST }^{\S} \text { vs placebo, } \\
\text { difference, } \%(95 \% \text { Cl) }\end{array}$ \\
\hline Headache & $15(4.6)$ & $17(5.3)$ & $32(5.0)$ & $10(6.3)$ & $-1.3(-5.4$ to 2.8$)$ \\
\hline Dizziness & $13(4.0)$ & $13(4.0)$ & $26(4.0)$ & $4(2.5)$ & $1.5(-1.4$ to 4.4$)$ \\
\hline Pruritus & $19(5.9)$ & $6(1.9)$ & $25(3.9)$ & $2(1.3)$ & $2.6(0.3$ to 4.9$)$ \\
\hline Oxygen saturation decreased & $18(5.6)$ & $5(1.5)$ & $23(3.6)$ & $1(0.6)$ & 3.0 (1.1 to 4.9$)$ \\
\hline Hypotension & $10(3.1)$ & $6(1.9)$ & $16(2.5)$ & $5(3.2)$ & $-0.7(-3.7$ to 2.3$)$ \\
\hline Constipation & $19(5.9)$ & $1(0.3)$ & $20(3.1)$ & 0 & $3.1(1.8$ to 4.4$)$ \\
\hline Somnolence & $3(0.9)$ & $5(1.5)$ & $8(1.2)$ & $3(1.9)$ & $-0.7(-3.0$ to 1.6$)$ \\
\hline Confusional state & $8(2.5)$ & $1(0.3)$ & $9(1.4)$ & $1(0.6)$ & $0.8(-0.7$ to 2.3$)$ \\
\hline Insomnia & $5(1.5)$ & 0 & $5(0.8)$ & 0 & 0.8 (0.1 to 1.5$)$ \\
\hline \multicolumn{6}{|c|}{$\begin{array}{l}\text { †Related AEs are defined as possibly or probably related to study drug. } \\
\text { ¥A subset of patients who received two doses of SST } 15 \mathrm{mcg} \text { within } 20-25 \mathrm{~min} \text { (30-mcg dose equivalent). } \\
\text { \$SST includes } 15 \mathrm{mcg}(n=323) \text { and } 30 \mathrm{mcg}(n=363) \text { doses. } \\
\mathbb{I}_{\text {IAE mapping was based on Medical Dictionary for Regulatory Activities version } 11.0 \text {. }} \\
\text { AE: Adverse event; NA: Not applicable; SST: Sufentanil sublingual tablet. }\end{array}$} \\
\hline
\end{tabular}

\begin{tabular}{|c|c|c|c|c|c|c|}
\hline Serious $\mathrm{AE}^{\dagger}$ ( $\mathrm{n}=1$ each) & Study type & Treatment & Severity & $\begin{array}{l}\text { Relationship to } \\
\text { treatment }\end{array}$ & Outcome & Ref. \\
\hline Angina pectoris & $\begin{array}{l}\text { Phase III; open-label; } \\
\text { emergency department }\end{array}$ & SST $30 \mathrm{mcg}$ & Moderate & Possibly related & $\begin{array}{l}\text { Dose not changed and patient } \\
\text { recovered }\end{array}$ & [21] \\
\hline Atrial fibrillation & $\begin{array}{l}\text { Phase III; placebo-controlled; } \\
\text { orthopedic surgery }\end{array}$ & SST $15 \mathrm{mg}$ & Moderate & Not related & $\begin{array}{l}\text { Dose not changed and patient } \\
\text { recovered }\end{array}$ & [16] \\
\hline Confusional state $\mathrm{e}^{\ddagger}$ & $\begin{array}{l}\text { Phase III; placebo-controlled; } \\
\text { orthopedic surgery }\end{array}$ & SST $15 \mathrm{mcg}$ & Moderate & Possibly related & $\begin{array}{l}\text { Dose not changed and patient } \\
\text { recovered }\end{array}$ & [16] \\
\hline Hemiparesis & $\begin{array}{l}\text { Phase III; placebo-controlled; } \\
\text { abdominal surgery }\end{array}$ & Placebo & Severe & Possibly related & $\begin{array}{l}\text { Drug withdrawn and patient } \\
\text { recovered }\end{array}$ & [19] \\
\hline Hypoxia $\ddagger$ & $\begin{array}{l}\text { Phase III; placebo-controlled; } \\
\text { orthopedic surgery }\end{array}$ & SST $15 \mathrm{mcg}$ & Moderate & Not related & $\begin{array}{l}\text { Dose not changed and patient } \\
\text { recovered }\end{array}$ & [16] \\
\hline Oxygen saturation decreased ${ }^{\S}$ & $\begin{array}{l}\text { Phase III; placebo-controlled; } \\
\text { orthopedic surgery }\end{array}$ & SST $15 \mathrm{mcg}$ & Severe & Probably related & $\begin{array}{l}\text { Drug withdrawn and patient } \\
\text { recovered }\end{array}$ & [16] \\
\hline Postoperative ileus & $\begin{array}{l}\text { Phase III; active comparator; } \\
\text { mixed surgery }\end{array}$ & SST $15 \mathrm{mcg}$ & Severe & Not related & $\begin{array}{l}\text { Dose not changed and patient } \\
\text { recovered }\end{array}$ & [18] \\
\hline Pulmonary embolism $\ddagger$ & $\begin{array}{l}\text { Phase III; placebo-controlled; } \\
\text { orthopedic surgery }\end{array}$ & SST $15 \mathrm{mcg}$ & Mild & Not related & $\begin{array}{l}\text { Dose not changed and patient } \\
\text { recovered }\end{array}$ & [16] \\
\hline Syncope & $\begin{array}{l}\text { Phase III; placebo-controlled; } \\
\text { abdominal surgery }\end{array}$ & Placebo & Moderate & Possibly related & $\begin{array}{l}\text { Drug withdrawn and patient } \\
\text { recovered }\end{array}$ & [19] \\
\hline \multicolumn{7}{|c|}{$\begin{array}{l}{ }^{\dagger} \text { A serious AE was defined as any event that was fatal or life-threatening, permanently or substantially disabling or incapacitating (i.e., substantial disruption of ability to conduct } \\
\text { normal life functions), prolonged hospitalization, a congenital anomaly or was an important medical event. } \\
\text { †Three of the serious AEs (confusional state, hypoxia and pulmonary embolism) occurred in the same patient. } \\
\S \text { Oxygen saturation }=40 \% \text { (naloxone administered). } \\
\text { AE: Adverse event; SST: Sufentanil sublingual tablet. }\end{array}$} \\
\hline
\end{tabular}

Vital signs \& clinical laboratory results

Across the studies, mean changes from baseline in respiration rate were generally small and not clinically meaningful. No dose-dependent increase in percent of patients with an oxygen desaturation event was observed with SST, determined by comparing the total 24-h SST dose exposure $(<300 \mathrm{vs} \geq 300 \mathrm{mcg})$ in studies of at least $24 \mathrm{~h}$ in duration (Table 5) $[16,17,19,23]$.

Median drug utilization: morphine equivalent per SST dose based on duration of exposure

The morphine equivalent per SST dosage strength was determined utilizing dosing data from 357 patients in the active-comparator study [18] (SST $15 \mathrm{mcg}[\mathrm{n}=177]$ vs IV morphine PCA [n = 180]) (Table 6). Within the first $5 \mathrm{~h}$ after initiation of the first dose of treatment with SST $15 \mathrm{mcg}$ PCA or IV morphine PCA (the time during which active morphine metabolites will not yet have accumulated and exerted analgesic effects) [27], SST 15 mcg 


\begin{tabular}{|c|c|c|c|c|}
\hline \multirow[t]{2}{*}{ Patients, $\mathrm{n}(\%)$} & \multicolumn{2}{|c|}{ SST 15 mcg studies ${ }^{\dagger}$} & \multicolumn{2}{|c|}{ SST $30 \mathrm{mcg}$ studies } \\
\hline & $\begin{array}{l}<300 \mathrm{mcg} \\
(0-24 \mathrm{~h}) \\
(\mathrm{n}=107)\end{array}$ & $\begin{array}{l}\geq 300 \mathrm{mcg} \\
(0-24 \mathrm{~h}) \\
(\mathrm{n}=180)\end{array}$ & $\begin{array}{l}<300 \mathrm{mcg} \\
(0-24 \mathrm{~h}) \\
(\mathrm{n}=81)\end{array}$ & $\begin{array}{l}\geq 300 \mathrm{mcg} \\
(0-24 \mathrm{~h}) \\
(\mathrm{n}=26)\end{array}$ \\
\hline \multicolumn{5}{|c|}{ Oxygen saturation, \% } \\
\hline$\geq 95$ & $72(67.3)$ & $139(77.2)$ & $59(72.8)$ & $23(88.5)$ \\
\hline 93-94 & $18(16.8)$ & $26(14.4)$ & $15(18.5)$ & $2(7.7)$ \\
\hline $90-92$ & $10(9.3)$ & $11(6.1)$ & $7(8.6)$ & 0 \\
\hline$<90$ & $7(6.5)$ & $4(2.2)$ & 0 & $1(3.8)$ \\
\hline Mean (SD) & $93.5(6.2)$ & $94.5(1.7)$ & $95.2(1.6)$ & $95.4(2.2)$ \\
\hline Median & 95.0 & 95.0 & 96.0 & 96.0 \\
\hline Min, $\max$ & $(40,100)$ & $(83,99)$ & $(91,98)$ & $(86,98)$ \\
\hline
\end{tabular}

\begin{tabular}{|c|c|c|c|}
\hline Hours & Median SST usage $^{\dagger}(n=177)^{\ddagger}$ & Median IV morphine usage $(n=180)^{\ddagger}$ & $\begin{array}{l}\text { Morphine equivalent per } \\
\text { SST dosage strength }\end{array}$ \\
\hline Hours 0-5 & $90.0 \mathrm{mcg}$ & $15.0 \mathrm{mg}$ & $\begin{array}{l}\text { SST } 15 \mathrm{mcg}=2.5 \mathrm{mg} \text { IV MS } \\
\text { SST } 30 \mathrm{mcg}=5.0 \mathrm{mg} \text { IV MS }\end{array}$ \\
\hline Hours 0-48 & $525.0 \mathrm{mcg}$ & $61.5 \mathrm{mg}$ & $\begin{array}{l}\text { SST } 15 \mathrm{mcg}=1.8 \mathrm{mg} \text { IV MS } \\
\text { SST } 30 \mathrm{mcg}=3.5 \mathrm{mg} \text { IV MS }\end{array}$ \\
\hline
\end{tabular}

was calculated to be equal to approximately $2.5 \mathrm{mg}$ IV morphine based on drug utilization in each treatment group over this 5 -h period (or $5 \mathrm{mg}$ IV morphine for 30-mcg SST).

Time to dissolution of SST

In the SST 15 mcg PK study [26] where time of tablet erosion was monitored, the tablet began to dissolve immediately once it was placed under the tongue and the mean and median erosion times for sublingual placement of the SST were 6.2 and $5 \mathrm{~min}$ (range 4-16), respectively, with little movement in the tablet location. It should be noted that approximately $22 \%$ of the SST formulation is water-insoluble, non-nutritive excipients (i.e., dicalcium phosphate anhydrous, stearic acid and magnesium stearate), which do not fully dissolve in water or saliva and must be ultimately washed away by swallowing. Sufentanil absorption by subjects with very fast or slow times of erosion were not dissimilar (data not shown), suggesting that erosion time does not have a substantial influence on efficacy or safety.

\section{Discussion}

Pooled results from ten clinical trials, in which patients were treated with SST 30 and $15 \mathrm{mcg}$ for $\leq 72 \mathrm{~h}$, indicate that SST has a tolerable safety profile, with most AEs considered mild or moderate in severity. As expected, a significantly greater proportion of patients in the SST group compared with the placebo group experienced $\geq 1$ treatment-related AE; this difference was not significant when considering AEs overall. The pooled safety population included SST 15-mcg exposure considered equivalent to or higher than SST $30 \mathrm{mcg}$ (two SST 15-mcg tablets dosed within $20-25$ min of each other, with a third dose often occurring within the hour). Overall, safety assessments indicate that AEs are similar to those observed with other opioids in postoperative studies $[6,18]$ and no dose-dependent increases in oxygen desaturation events were observed with SST. Most of the respiratory events observed with SST were mild to moderate and self-limited, and naloxone was not required for any patient receiving 
SST $30 \mathrm{mcg}$ and required by three patients receiving SST $15 \mathrm{mcg}$. Of note, two additional patients in the placebo arms required naloxone.

IV morphine is commonly used in the management of moderate-to-severe acute pain in a hospital setting. However, morphine has been associated with cognitive adverse effects including impaired recall, delayed reaction time and impaired memory [28-30]. In contrast, the study of patients in the emergency department showed no evidence of cognitive impairment following treatment with SST $30 \mathrm{mcg}$ [21]. In that study, 75 patients were evaluated predose and postdose on the six-item screener to identify cognitive impairment and most patients (97.3\%) had the same or improved score following SST 30-mcg treatment. Furthermore, the active-comparator study showed a lower rate of oxygen desaturation events over the 72-h study period for patients who received SST $15 \mathrm{mcg}$ PCA compared with patients receiving IV morphine PCA [18]. In that same study, no significant differences in overall AEs were observed between treatment arms.

In addition to a potentially improved tolerability profile, SST also offers a distinct advantage over IV morphine with regard to route of administration, as patients generally prefer oral administration of medication over IV or intramuscular administration [31-33]. However, swallowed oral opioid tablets are typically limited by slow onset of action [34]. Sufentanil has a rapid penetration of the blood-brain barrier compared with hydromorphone and morphine, as reflected by the equilibration half-life between plasma and the CNS (6, 46 and 168 min, respectively) $[8,27,35]$. Clinical trials have demonstrated significant reductions in pain intensity occurring within 15-30 min of SST administration $[16,17,19-21,36]$. In the active-comparator SST $15 \mathrm{mcg}$ study, patients reported improved pain control with SST 15-mcg PCA compared with IV morphine PCA following major orthopedic or open abdominal surgery [18]. In this study, clinically meaningful analgesia (defined as a pain intensity difference from baseline of 1.3 for acute pain [37]) was observed after $1.3 \mathrm{~h}$ in the SST 15-mcg PCA group compared with $7 \mathrm{~h}$ in the IV morphine PCA group. In this study, a SST 15 -mcg dose was initially equivalent to $2.5 \mathrm{mg}$ of IV morphine when use was averaged over the first $5 \mathrm{~h}$, but dropped to an equivalent of $1.8 \mathrm{mg}$ of IV morphine over $48 \mathrm{~h}$. This apparent lowering of SST potency over time compared with morphine is likely due to active morphine metabolite accumulation. Patients with normal renal function after $48 \mathrm{~h}$ of exposure to IV morphine PCA had an average morphine-6-glucuronide plasma concentration of $20 \mathrm{ng} / \mathrm{m}$, similar to their average morphine sulfate concentration of $22 \mathrm{ng} / \mathrm{ml}[18]$.

\section{Limitations}

Not all studies of SST were placebo-controlled and no study of SST $30 \mathrm{mcg}$ included an active comparator, which may limit the ability to interpret these results. This pooled analysis also included patients in SST $15 \mathrm{mcg}$ PCA studies who received two doses of SST $15 \mathrm{mcg}$ within the first 25 min of the study. Furthermore, $75 \%$ of these patients also received a third dose of SST $15 \mathrm{mcg}$ in the first hour of treatment, exceeding by $50 \%$ the dose of sufentanil received from a single SST 30-mcg dose given per hour. Overall, the 24-h median (range) SST dose amount utilized was 1.8-times higher for the SST 15-mcg $(375 \mathrm{mcg})$ group compared with the SST 30-mcg $(210 \mathrm{mcg})$ group. The increased rate of AEs for these SST 15-mcg patients (compared with the SST 30-mcg groups) is likely due to this higher exposure as well as demographic factors, such as, increased age and higher BMIs. Further, it should also be noted that patients in the SST 15 mcg PCA studies had undergone longer, more complicated surgeries (knee/hip replacement or open abdominal surgery), with the expectation of requiring 2-3 days of acute pain management within a hospital setting. In contrast, the majority of patients in the SST 30 mcg studies were outpatient or short-stay (primarily laparoscopic) surgery and often discharged home at 12-24 h postoperatively. Last, long-term consequences of opioid treatment, such as tolerance or addiction, were not identified in these short-term studies; however, the labeled use of SST is for no more than 2-3 days duration in medically supervised and monitored settings.

\section{Conclusion}

While a significantly greater proportion of patients in the SST group compared with the placebo group experienced $\geq 1$ treatment-related $\mathrm{AE}$, the overall findings from the pooled analysis support that short-term $(\leq 72 \mathrm{~h})$ administration of SST is well tolerated-with most AEs considered mild or moderate in severity-for the treatment of moderate-to-severe acute pain in medically supervised settings. 
Author contributions

All the authors analyzed and interpreted the data, drafted or revised the manuscript for important intellectual content and provided approval of the final version. Y-K Chiang was involved in the study design and carried out data analyses of the original studies included in this analysis. PP Palmer and KP DiDonato were involved in data acquisition and PP Palmer was also involved in study concept and design.

Financial \& competing interests disclosure

The SST 30 mcg studies were funded by AcelRx Pharmaceuticals and were funded in part by the Clinical and Rehabilitative Medicine Research Program (CRMRP) of the US Army Medical Research and Materiel Command (USAMRMC) under contract no. W81XWH15-C-0046 and no. W81XWH-11-1-0361. JR Miner and D Leiman are consultants to AcelRx. JR Miner, TI Melson and D Leiman received research funding from AcelRx. HS Minkowitz is a consultant for and has received research support from AcelRx, Trevana, Heron, Durect, Acacia, Avenue, Recro and Innocoll, and has also received research support from Sorrento, Semnur, Merck, SPR, Pfizer, and Sollis. YK Chiang is a paid statistical consultant for AcelRx. KP DiDonato and PP Palmer are employees and have stock ownership of AcelRx. The authors have no other relevant affiliations or financial involvement with any organization or entity with a financial interest in or financial conflict with the subject matter or materials discussed in the manuscript apart from those disclosed.

Writing and editorial assistance were provided by R Steger and P Baron (BlueMomentum, an Ashfield Company, part of UDG Healthcare plc) and funded by AcelRx Pharmaceuticals.

Ethical conduct of research

The protocols for all clinical studies used to generate data for the current analysis were approved by the corresponding Institutional Review Board for each study site and written informed consent was obtained from all patients.

Open access

This work is licensed under the Attribution-NonCommercial-NoDerivatives 4.0 Unported License. To view a copy of this license, visit http://creativecommons.org/licenses/by-nc-nd/4.0/

Data sharing statement

The authors certify that this manuscript reports the secondary analysis of clinical trial data that have been shared with them, and that the use of this shared data is in accordance with the terms (if any) agreed upon their receipt. The source of this data is: Clinicaltrials.gov identifiers: NCT02356588, NCT02662556, NCT02447848, NCT00859313, NCT00612534, NCT00718081, NCT01539538, NCT01539642 and NCT01660763.

\section{References}

Papers of special note have been highlighted as: $\bullet$ of interest; $\bullet \bullet$ of considerable interest

1. Sommer M, De Rijke JM, Van Kleef M et al. The prevalence of postoperative pain in a sample of 1490 surgical inpatients. Eur. J. Anaesthesiol. 25(4), 267-274 (2008).

2. Gerbershagen HJ, Aduckathil S, van Wijck AJ, Peelen LM, Kalkman CJ, Meissner W. Pain intensity on the first day after surgery: a prospective cohort study comparing 179 surgical procedures. Anesthesiology 118(4), 934-944 (2013).

3. McCaig LF, Stussman BJ. National Hospital Ambulatory Medical Care Survey: 1996 emergency department summary. National Center for Health Statistics (1997). www.cdc.gov/nchs/data/ad/ad293.pdf

4. Centers for Disease Control (CDC). Emergency department visits (2015). www.cdc.gov/nchs/fastats/emergency-department.htm

5. Pitts S, Niska RW, Xu J, Burt C. National hospital ambulatory medical care survey: 2006 emergency department summary. National Center for Health Statistics (2008). www.cdc.gov/nchs/data/nhsr/nhsr007.pdf

6. Hutchison RW, Chon EH, Tucker WF et al. A comparison of a fentanyl, morphine, and hydromorphone patient-controlled intravenous delivery for acute postoperative analgesia: a multicenter study of opioid-induced adverse reactions. Hosp. Pharm. 41(7), 659-663 (2006).

7. Smith H. The metabolism of opioid agents and the clinical impact of their active metabolites. Clin. J. Pain. 27(9), 824-838 (2011).

8. Scott JC, Cooke JE, Stanski DR. Electroencephalographic quantitation of opioid effect: comparative pharmacodynamics of fentanyl and sufentanil. Anesthesiology 74(1), 34-42 (1991).

9. Lehmann KA, Gerhard A, Horrichs-Haermeyer G, Grond S, Zech D. Postoperative patient-controlled analgesia with sufentanil: analgesic efficacy and minimum effective concentrations. Acta Anaesthesiol. Scand. 35, 221-226 (1991).

10. Gardner-Nix J. Oral transmucosal fentanyl and sufentanil for incident pain. J. Pain Sympt. Manag. 22(2), 627-630 (2001).

11. Clark N, Meuleman T, Liu W, Zwanikken P, Pace N, Stanley T. Comparison of sufentanil-N2O and fentanyl-N2O in patients without cardiac disease undergoing general surgery. Anesthesiology 66(2), 130-135 (1987). 
12. Ved SA, Dubois M, Carron H, Lea D. Sufentanil and alfentanil pattern of consumption during patient-controlled analgesia: a comparison with morphine. Clin. J. Pain. 5(Suppl. 1), S63-S70 (1989).

13. Bailey PL, Streisand JB, East KA et al. Differences in magnitude and duration of opioid-induced respiratory depression and analgesia with fentanyl and sufentanil. Anesth. Analg. 70(1), 8-15 (1990).

14. Conti G, Arcangeli A, Antonelli M et al. Sedation with sufentanil in patients receiving pressure support ventilation has no effects on respiration: a pilot study. Can. J. Anesth. 51(5), 494-499 (2004).

15. Golembiewski J, Dasta J, Palmer PP. Evolution of patient-controlled analgesia: from intravenous to sublingual treatment. Hosp. Pharm. 51(3), 214-229 (2016).

16. Jove M, Griffin DW, Minkowitz HS, Ben-David B, Evashenk MA, Palmer PP. Sufentanil sublingual tablet system for the management of postoperative pain after knee or hip arthroplasty: a randomized, placebo-controlled study. Anesthesiology 123(2), 434-443 (2015).

-• Phase III, randomized, placebo-controlled study of patient-controlled sublingual sufentanil tablet 15 mcg following orthopedic surgery.

17. Ringold FG, Minkowitz HS, Gan TJ et al. Sufentanil sublingual tablet system for the management of postoperative pain following open abdominal surgery: a randomized, placebo-controlled study. Regional Anesth. Pain Med. 40(1), 22-30 (2015).

-• Phase III randomized, placebo-controlled study of patient-controlled sublingual sufentanil tablet 15 mcg in following abdominal surgery.

18. Melson TI, Boyer DL, Minkowitz HS et al. Sufentanil sublingual tablet system vs. intravenous patient-controlled analgesia with morphine for postoperative pain control: a randomized, active-comparator trial. Pain Pract. 14(8), 679-688 (2014).

-• Phase III randomized study of patient-controlled sublingual sufentanil tablet 15 mcg versus patient-controlled intravenous morphine following orthopedic or abdominal surgery.

19. Minkowitz HS, Leiman D, Melson T, Singla N, DiDonato KP, Palmer PP. Sufentanil sublingual tablet $30 \mathrm{mcg}$ for the management of pain following abdominal surgery: a randomized, placebo-controlled, phase-3 study. Pain Pract. 17(7), 848-858 (2017).

-. Phase III randomized, placebo controlled study of healthcare practitioner- administered sublingual sufentanil tablet $30 \mathrm{mcg}$ following abdominal surgery.

20. Hutchins JL, Leiman D, Minkowitz HS, Jove M, DiDonato KP, Palmer PP. An open-label study of sufentanil sublingual tablet $30 \mathrm{mcg}$ in patients with postoperative pain. Pain Med. 19(10), 2058-2068 (2018).

-• Phase III study of healthcare practitioner-administered sublingual sufentanil tablet 30mcg following surgery.

21. Miner JR, Rafique Z, Minkowitz HS, DiDonato KP, Palmer PP. Sufentanil sublingual tablet $30 \mathrm{mcg}$ for moderate-to-severe acute pain in the emergency department. Am. J. Emerg. Med. 36(6), 954-961 (2018).

-• Phase III study of healthcare practitioner-administered sublingual sufentanil tablet $30 \mathrm{mcg}$ in an emergency department setting.

22. Fisher DM, Chang P, Wada DR, Dahan A, Palmer PP. Pharmacokinetic properties of a sufentanil sublingual tablet intended to treat acute pain. Anesthesiology 128(5), 943-952 (2018).

-. Pharmacokinetic characteristics of sublingually administered sufentanil 15 and 30 mcg tablets were reported and then evaluated for consistency with the published clinical profile (i.e., analgesia onset and offset).

23. Minkowitz HS, Singla NK, Evashenk MA et al. Pharmacokinetics of sublingual sufentanil tablets and efficacy and safety in the management of postoperative pain. Regional Anesth. Pain Med. 38(2), 131-139 (2013).

- Describes the results of a pharmacokinetic study and two Phase II randomized, placebo-controlled studies of healthcare practitioner-administered sublingual sufentanil tablet at various doses (including $15 \mathrm{mcg}$ ) following orthopedic or abdominal surgery.

24. Boonstra AM, Stewart RE, Köke AJ et al. Cut-off points for mild, moderate, and severe pain on the numeric rating scale for pain in patients with chronic musculoskeletal pain: variability and influence of sex and catastrophizing. Front. Psychol. 7(1466), 1-9, [eCollection 2016] (2016).

25. Krebs EE, Carey TS, Weinberger M. Accuracy of the pain numeric rating scale as a screening test in primary care. J. Gen. Intern. Med. 22, 1453-1458 (2007).

26. Willsie SK, Evashenk MA, Hamel LG, Hwang SS, Chiang YK, Palmer PP. Pharmacokinetic properties of single- and repeated-dose sufentanil sublingual tablets in healthy volunteers. Clin. Ther. 37, 145-155 (2015).

27. Lötsch J, Skarke C, Schmidt H, Grosch S, Geisslinger G. The transfer half-life of morphine-6-glucuronide from plasma to effect site assessed by pupil size measurements in healthy volunteers. Anesthesiology 95, 1329-1338 (2001).

28. Zacny JP, Lichtor JL, Flemming D, Coalson DW, Thompson WK. A dose-response analysis of the subjective, psychomotor and physiological effects of intravenous morphine in healthy volunteers. J. Pharmacol. Exper. Ther. 268(1), 1-9 (1994).

29. Kerr B, Hill H, Coda B et al. Concentration-related effects of morphine on cognition and motor control in human subjects. Neuropsychopharmacology 5(3), 157-166 (1991).

30. Kamboj SK, Tookman A, Jones L, Curran HV. The effects of immediate-release morphine on cognitive functioning in patients receiving chronic opioid therapy in palliative care. Pain 117(3), 388-395 (2005). 
31. Alten R, Krüger K, Rellecke J et al. Examining patient preferences in the treatment of rheumatoid arthritis using a discrete-choice approach. Patient Prefer. Adherence 10, 2217-2228 (2016).

32. Eek D, Krohe M, Mazar I et al. Patient-reported preferences for oral versus intravenous administration for the treatment of cancer: a review of the literature. Patient Prefer. Adherence. 10, 1609-1621 (2016).

33. daCosta DiBonaventura M, Wagner JS, Girman CJ et al. Multinational Internet-based survey of patient preference for newer oral or injectable Type II diabetes medication. Patient Prefer. Adherence. 4, 397-406 (2010).

34. Smith H. A comprehensive review of rapid-onset opioids for breakthrough pain. CNS Drugs 26(6), 509-535 (2012).

35. Shafer SL, Flood PD. The pharmacology of opioids. In: Geriatric Anesthesiology (2nd Edition). Silverstein JH, Rooke A, Reves JG, McLeskey CH (Eds). Springer Science \& Business Media, NY, USA, 209-228 (2007).

36. Singla NK, Muse DD, Evashenk MA, Palmer PP. A dose-finding study of sufentanil sublingual microtablets for the management of postoperative bunionectomy pain. J. Trauma Acute Care Surg. 77(3 Suppl. 2), S198-S203 (2014).

37. Cepeda MS, Africano JM, Polo R, Alcala R, Carr DB. What decline in pain intensity is meaningful to patients with acute pain? Pain 105(1-2), 151-157 (2003). 
(

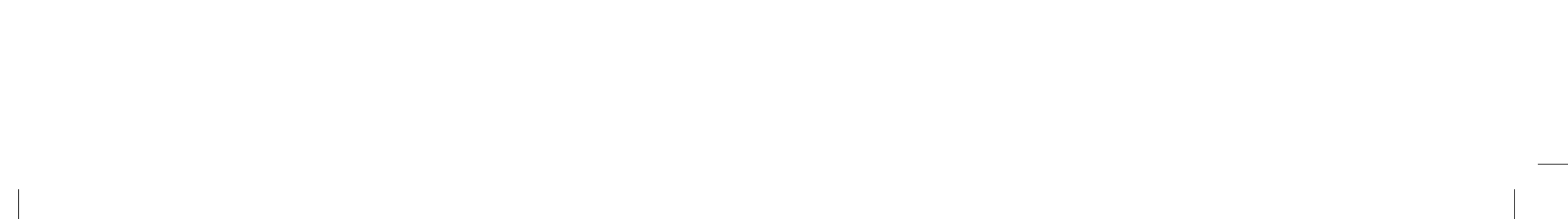

